\title{
The Experiences of Jordanian Employed Women in Health Sector after Returning from Maternity Leave a Qualitative Study
}

\author{
Ola Naiem Alfuqaha ${ }^{1^{*}}$ and Ruqayya Zeilani ${ }^{2}$ \\ ${ }^{1}$ Faculty of Nursing/Clinical Instructor, The Hashemite University, Jordan \\ ${ }^{2}$ Faculty of Nursing, The University of Jordan, Jordan
}

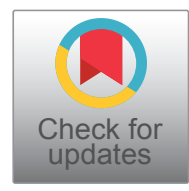

*Corresponding author: Ola Naiem Alfuqaha, Faculty of Nursing/Clinical Instructor, The Hashemite University, Zarqaa, Jordan

\begin{abstract}
Background: Women have played a very important part in the labor force and the term "feminization" has become very common in workplace. In Jordan the latest figures of the Public Institution for Social Security for the year 2012 indicate that the proportion of women who were involved in the organization has been nearly $25 \%$ of all the organization participants, many factors influence the levels of women's economic activity and which include both the legal frameworks and the socio-cultural perceptions (Department of Statistics, 2013).
\end{abstract}

Aims: The aim of this study is to explore the experience of worked women in hospitals after returning to work from maternity leave by focusing on (motherhood, family relationships, and role dynamics).

Methods: The descriptive phenomenology as a qualitative research design was adopted to describe the lived experiences of Nineteen Jordanian working women in the health sectors after returning from maternity leave it was selected purposefully from four hospitals in two Jordanian cities were willing to participate in this study.

Findings: Illustrate four main themes: A new life with burdens, errands and tasks, Eager and keen to sleep, Experiencing diverse emotions and experiencing the feeling of guilt, Requirements of multi roles mother (mothering/working): A trusted daycare, support system at home, and support system at work.

Conclusion: The transition to workplace after maternity leave needs some planning in order to facilitate their returning and achieve a high level of work- family balance.

Implication for nursing and health policy: Healthcare manager and policymakers call for to reconsider the period after child birth and maternity leave for the Jordanian working women. Extended the maternity leave to 5-6 month would positively affect the women's productivity at work and create new ways to achieving a breast feeding continuity and strengthening the mother's and children's health as well as the bond between them.

\section{Keywords}

Family role, Family support, Jordanian employed women, Maternity leave, Motherhood, Women role, Nurses experiences

Women have play a very important role in the labor work force. In Jordan the latest figures from the Public Institution for Social Security, year 2012, indicate that 25\% of participants were women this leads to the lifting of GDP (Gross Domestic Product) (Department of Statistics, 2013). Many factors influence the levels of women's economic activity including both legal frameworks and the sociocultural perceptions.

The aim of this study is to explore the experience of working women in hospitals, post maternity leave; the focus being on motherhood, family relationships, and role dynamics. This descriptive phenomenology research design was adopted to describe the lived experiences of Jordanian working women in the health sectors after returning from maternity leave. The total number of participants in this study was 19 Jordanian women.

The findings illustrate two main themes:

A. New life with burdens; sleeplessness.

B. Requirements of multi roles mother (mothering/working): a trusted daycare, support system at home, and support system at work.

Citation: Alfuqaha ON, Zeilani R (2019) The Experiences of Jordanian Employed Women in Health Sector after Returning from Maternity Leave a Qualitative Study. Int J Womens Health Wellness 5:103. doi.org/10.23937/2474-1353/1510103

Accepted: September 24, 2019: Published: September 26, 2019

Copyright: (c) 2019 Alfuqaha ON, et al. This is an open-access article distributed under the terms of the Creative Commons Attribution License, which permits unrestricted use, distribution, and reproduction in any medium, provided the original author and source are credited. 


\section{Introduction}

Motherhood is considered the most critical stage in the life of working women because it is at this stage that women experience a high level of obstacles related to the conflicting demands of their parenting and working outside of the home [1].

Women have played a very important part in the labor force such that the term "feminization" has become very common in workplace. Feminization, in this context, refers to the rising rate of female participation in the labor force such as, medicine, law and business [2].

Returning to work after maternity leave is challenging. Many employed women need support such as flexible working hours and flexibility in starting times. In addition, emotional and social support is needed as these women have very specific needs related to recent childbirth [3].

In Jordan, an analytical study carried out by the General Secretariat of the Higher Population Council (HPC), 2013, found that the most important characteristics of this study is the discussion of the transitional phase of a women's life as she moves through marriage and motherhood. The HPCs study has highlighted these two stages in women's life and work opportunities because of the significant impact these stages have on Jordanian economic decisions and the level of fertility. The main findings of this study indicate that only $14 \%$ of the labor market is impacted by women (Department of Statistics, 2013).

The presence of women in public and health care sectors has become clear and important in Jordan. The proportion of women physicians in the Jordanian Healthcare Sector in 2007 reached to 15.5\%. Total percentage of female pharmacists $33 \%$, nurses $54 \%$ and dentists 54\% [4]. In addition, the latest figures of the Public Institution for Social Security for the year 2012 indicate that the proportion of women who were involved in the organization was nearly $25 \%$ of all the organization participants (Department of Statistics, 2013).

The women significantly contribute to the economic well-being of a number of unpaid work, such as child-rearing and the completion of a home business which is not counted in GDP; despite the fact that women always allocate more time to do household tasks and take care of children which in turn is considered to be one of the main reasons for the lack of women's participation in the labor market [5].

Work-life balance is a term some mothers use to created boundaries in their jobs so that they could allocate more time to take care of their children [6]. On the other hand, they do not want their workloads to influence motherhood or affect their bonds with their children [6].
Studies focused on the experience of employed women during and after childbirth showed that women who experienced negative events in the workplace during their pregnancy and had pregnancy complications felt frustrated and challenged. The majority mentioned that they started to think seriously about the decision of continuing their work or staying with their new baby in order to satisfy their motherhood role $[6,7]$. Fursman [7] suggested that the workplaces of some women often focus only on their work role, consider the job as the priority, and do not recognize or validate outside commitments or priorities of her motherhood duties.

Working mothers must arrange for baby sitters or child care centers to care their children while working outside the home. Liu, Chen, and Anderson [8] used the "Fragile Families and Child Wellbeing (FFCW)" this study focuses on child care and its association with mothers who work outside their homes. The findings revealed that mothers who have changed their child care arrangements were more likely to quit their job because the stability of care is linked to the stability of the "mothers' job".

Employed mothers however, describe the challenge of combining motherhood and employment with few structural supports [9]. Women have to play their roles as an individual, as mothers, as wives and as workers which in turn poses a greater pressure upon them in the sense that they have many duties and responsibilities at home and at place of work [10].

Based on several studies in the Arab countries, working mothers tended to suffer from increased family demand, minimal social activities and decreased family interactions due to work and child care overload (Algerian society for Nadia, 2012).

The women's role is increased in Jordan, but the indicators show a delay in women's role than men in many areas, including the labor market (Ministry of Policy, Planning and the Ministry of Labor, 2010).

There are many factors that affect returning to work after maternity leave. Some of these include financial status of the family and the social support they should have from their home environment. Challenges related to returning to work negatively impact women in the labor force and likely decrease the number of children they will have. This gap has been obviously noted in the literature review. In Jordan, there is a limited number of studies' regarding to the experiences of worked women after maternal leave.

In fact, the economic participation rates for Jordanian women are low in the labor market and unemployment rates are high; especially among young educated women. The number of constraints and limitations 
stand as an obstacle to the participation of the Jordanian women in the labor market.

This study is the first of its kind to shed light on the experiences of Jordanian women working in the healthcare who provide direct care to patients after her return from maternity leave. This study takes into consideration her relationship or her bond with her children and her husband. The aim of this study is to explore the experience of working women in hospitals after returning to work from maternity leave by focusing on motherhood, family relationships, and role dynamics. The objectives of this study are:

1. Describe the women's experience of motherhood after returning from maternal leave.

2. Describe the women's experience of family dynamics, and social relationships with family members after returning to work from maternal leave.

\section{Methodology}

The descriptive phenomenology as a qualitative research design was adopted to describe the lived experiences of Jordanian working women in healthcare after returning from maternity leave. The total number of participants in this study was 19 Jordanian women. The sample was selected purposefully according to inclusion criteria from four hospitals in two Jordanian cities.

The participants in this study were selected according to the following inclusion criteria: each participant is a full time health care provider employed at one of the selected hospitals in this study such as physicians, pharmacists, dentists, and nurses. Furthermore, each participant should be resuming her job after her maternity leave within the time period of three months to one year after giving birth. The participant's age > 24-years-old, has at least earned a bachelor's degree level of education, and willing to share her experience with the researcher. Exclusion criteria included
non-Jordanians, pregnant women and women that returned to work more than a year ago following childbirth.

\section{Ethical consideration}

The study was approved prior to data collection by the Center of Women's Study in the University of Jordan, the IRB of the Ministry of Health in Jordan, and the Jordan University Hospital. All participants were informed of their right to decide whether or not to participate in this study. Each participant received a consent form prior to her participation to be read and signed upon her approval to participate. The researcher contacted appropriate administrative personnel to facilitate research with the physicians, pharmacists, dentists, and nurses in the four hospitals. Data was collected in depth semi-structured interviews. The interviews were conducted by the researcher from June to December, 2015.

All interviews were recorded and transcribed using Arabic language into a written text before being analyzed on the same day or the next day of the interview. Then they were translated into English language by the professional translator. These steps were done in order to maintain the categorization of the continuously growing data. The transcription was word-forword and the researcher was also writing her reflections based on the interview in addition to the interview transcription. The Qualitative content analysis was used to analyze the data that was collected by the interviews.

\section{Findings}

The experience of the Jordanian women working in Healthcare following 10 or 12 weeks of maternity leave showed the importance of social support which facilitates the transition from maternal life into the new life as a working mother. The demographic data of the

Table 1: Participants' characteristics.

\begin{tabular}{|c|c|c|c|c|c|c|c|c|}
\hline Participant & Age & $\begin{array}{l}\text { Months } \\
\text { returned to } \\
\text { work }\end{array}$ & $\begin{array}{l}\text { Time of } \\
\text { interview }\end{array}$ & Hospital & Specialty & $\begin{array}{l}\text { Number of } \\
\text { children }\end{array}$ & $\begin{array}{l}\text { Years of } \\
\text { experience }\end{array}$ & $\begin{array}{l}\text { Type of } \\
\text { delivery }\end{array}$ \\
\hline Women A & 29 & $3 \mathrm{M}$ & $2 \mathrm{M}$ & A & Pharmacist & 2 & 6 years & Normal \\
\hline Women B & 30 & $3 \mathrm{M}$ & $2 \mathrm{M}$ & A & Registered nurse & 1 & 6 years & Caesarea \\
\hline Women C & 29 & $3 \mathrm{M}$ & $2 \mathrm{M}$ & A & Registered nurse & 2 & 8 years & Caesarea \\
\hline Women D & 27 & $1 \mathrm{M}$ & $3 \mathrm{M}$ & A & Physician & 1 & 3 years & Normal \\
\hline Women E & 28 & $1 \mathrm{M}$ and 1 week & $4 \mathrm{M}$ & A & Physician & 1 & 5 years & Normal \\
\hline Women F & 29 & $1 \mathrm{M}$ & $6 \mathrm{M}$ & A & Physician & 1 & 4 years & Caesarea \\
\hline Women G & 26 & 21 days & $4 \mathrm{M}$ & A & Physician & 1 & 2 years & Normal \\
\hline Women $\mathrm{H}$ & 24 & $3 \mathrm{M}$ & $6 \mathrm{M}$ & $B$ & Registered nurse & 1 & 2 YEARS & Normal \\
\hline Women I & 27 & $3 \mathrm{M}$ & $5 \mathrm{M}$ & A & Registered nurse & 1 & 7 years & Caesarea \\
\hline Women J & 39 & $3 \mathrm{M}$ & $4 \mathrm{M}$ & C & Registered nurse & 4 & 16 years & Normal \\
\hline Women $\mathrm{K}$ & 41 & $3 \mathrm{M}$ & $1 \mathrm{M}$ & $B$ & pharmacist & 4 & 18 years & Caesarea \\
\hline Women L & 27 & $3 \mathrm{M}$ & $1 \mathrm{M}$ & $B$ & Registered nurse & 2 & 5 years & Normal \\
\hline
\end{tabular}




\begin{tabular}{|l|l|l|l|l|l|l|l|l|}
\hline Women M & 39 & $4 \mathrm{M}$ & 3 weeks & B & Pharmacist & 3 & 15 years & Caesarea \\
\hline Women N & 25 & $3 \mathrm{M}$ & $6 \mathrm{M}$ & $\mathrm{D}$ & Registered nurse & 1 & 5 years & Normal \\
\hline Women O & 30 & $3 \mathrm{M}$ & $4 \mathrm{M}$ & A & Registered nurse & 1 & 4 years & Caesarea \\
\hline Women P & 43 & $3 \mathrm{M}$ & $5 \mathrm{M}$ & $\mathrm{C}$ & Registered nurse & 5 & 20 years & Normal \\
\hline Women Q & 27 & $3 \mathrm{M}$ & $7 \mathrm{M}$ & $\mathrm{C}$ & Registered nurse & 2 & 5 years & Caesarea \\
\hline Women R & 30 & $3 \mathrm{M}$ & $1 \mathrm{M}$ & $\mathrm{A}$ & Registered nurse & 2 & 7 years & Normal \\
\hline Women S & 35 & $4 \mathrm{M}$ & $5 \mathrm{M}$ & A & Pharmacist & 4 & 11 years & Normal \\
\hline
\end{tabular}

Table 2: Themes, sub-themes and codes of Jordanian worked women's experiences after return from maternity leave.

\begin{tabular}{|c|c|c|}
\hline Themes & Sub theme & Codes \\
\hline $\begin{array}{l}\text { A new life loaded } \\
\text { with duties and } \\
\text { responsibilities }\end{array}$ & $\begin{array}{l}\text { - The challenges of coping with new } \\
\text { responsibilities and roles. } \\
\text { - } \text { struggle to perform routine self-care and feel } \\
\text { exhaustion and tired most of the time } \\
\text { - Lack of time for self and other social } \\
\text { relationships. } \\
\text { changing in the priorities of caretaking for family } \\
\text { members (husband, new baby, other children) }\end{array}$ & $\begin{array}{l}\text { - } \text { - } \text { Mew experience with new mothering role } \\
\text { - } \quad \text { Difficult adaptation with new role } \\
\text { - } \quad \text { Multi tasks need more Time } \\
\text { - } \quad \text { Take care of other children } \\
\text { - } \quad \text { Focus on new baby and } \\
\text { forget eating and home care } \\
\text { - } \quad \text { thinking of child care and make it the first } \\
\text { - } \quad \text { priority when return to home } \\
\text { - } \quad \text { nuclear family } \\
\text { - } \quad \text { Stopysical tired and no time for relax } \\
\text { - } \quad \text { struggling with time management } \\
\text { - } \quad \text { noticed a change in their relationships with } \\
\text { their husband, other children, her self }\end{array}$ \\
\hline $\begin{array}{l}\text { Short maternity } \\
\text { leave }\end{array}$ & $\begin{array}{l}\text { - Need to more maternal leave } \\
\text { - } \quad \text { Need more vacation } \\
\text { - Chillenges to balance between work and } \\
\text { - Smallness baby and need to mother care }\end{array}$ & $\begin{array}{l}\text { - } 3 \text { months of maternity leave is little } \\
\text { - My baby still weak and need to me and } \\
\text { continuo to breast feeding } \\
\text { - } \text { Asked to extend maternal leave } \\
\text { - Department needs take priorities and no } \\
\text { vacation } \\
\text { - Long time hours of work and overload in work } \\
\text { environment }\end{array}$ \\
\hline $\begin{array}{l}\text { The need for a } \\
\text { trusted day care }\end{array}$ & $\begin{array}{l}\text { - feeling miss trust with nursery services (bad } \\
\text { hygiene, crowded area, more children and no } \\
\text { stuff responsible) } \\
\text { - } \text { negative previous experience with other colleges } \\
\text { - } \quad \text { preference is given to baby setter to help with } \\
\text { child care rather than nursery } \\
\text { - } \\
\text { - } \text { Inced to have transportation (the new child). }\end{array}$ & $\begin{array}{l}\text { - } \quad \text { Negative rumors about nursery } \\
\text { - } \quad \text { Search for a place for child care. } \\
\text { - } \quad \text { Nanny tack care of 6-7 children at the same } \\
\text { - } \quad \text { Gime. } \\
\text { - } \quad \text { Child caught illness from nursery }\end{array}$ \\
\hline $\begin{array}{l}\text { Intervene with } \\
\text { work and the } \\
\text { need to support }\end{array}$ & $\begin{array}{l}\text { Wanting people to help with child care and } \\
\text { support in domestic works } \\
\text { the family help and supporting who help with } \\
\text { child-care is benefit } \\
\text { - the importance of husband support in domestic } \\
\text { and childcare } \\
\text { - the importance of work support (department, } \\
\text { supervisor, colleges) }\end{array}$ & 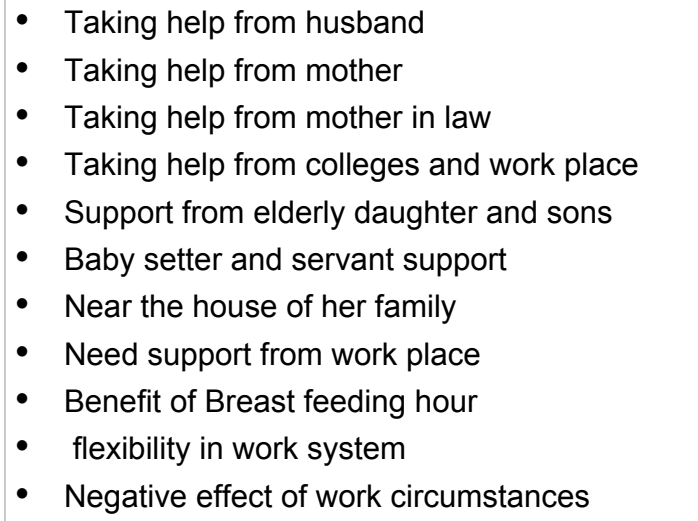 \\
\hline
\end{tabular}


women participated in this study was summarized in Table 1 (Participants' Characteristics).

These two main themes are:

Theme 1: A new life with burdens, errands and tasks; struggling between being a working woman and being a nursing mother. Challenges to balance between work and childcare, need more maternity leave.

Theme 2: Requirements of multiple roles (mothering/working): They struggle to find a suitable child care center the intervention of work with their lives, so they face various challenges throughout their transition from their maternal life into the new life and need to support. The findings revealed two themes that are summarized in Table 2 (Themes, sub-themes and codes of Jordanian worked women's experiences after return from maternity leave).

\section{Theme 1: A new life with burdens, errands and tasks}

Struggling between being a working woman and being a nursing mother: Participants in this study discussed the issue of having a new life after returning back to work. They expressed that they experience a heavy burden in their life related to the increased duties and responsibilities required from the working mother both at home and at work. Participants described this burden as extraordinary and heavy that changed the way they view life, leisure and work. Getting back to work after maternity leave places many tasks on the participants' shoulders. They were torn between work duties and home responsibilities. Participants stated that when the working woman arrives at home after heavy working hours, she is faced with the waiting responsibilities at home: taking care of her child, doing housework, and cooking. Later when the woman feels that she has some time to take a rest, she realizes that taking care of her husband and other children is a job that should be fulfilled. The new life of the participants requires adapting to the obligation of the new demands of their new life, as mothers, wives and as working women. Some women mentioned the overwhelming responsibilities that made their new life difficult. One participant said:

"The life of a working woman is difficult; mainly if she came back to work after having few weeks of maternity leave, it is difficult to coordinate between work responsibilities and being a mother, having children, social occasions, and duties. Honestly, our life is a combating" (woman S).

There are two categories of participants in this study; some of the participants were first time mothers and others had children previously. For the participants who were mothers for the first time, they found it difficult to cope with the new role as a mother and this affected their relationship with their husbands.
New mothers need more time to cope with their life or otherwise they will feel unsatisfied with their lives due to these changes. These changes include new responsibilities, changes in body image, and unfamiliar environment. As one of the participants stated:

"Before having the baby, taking care of myself was the most important thing to me. Now, I don't have enough time to take care of myself, neglecting my appearance and my husband was complaining about this all of the time... I can't look as I used to do in the past because of the new responsibilities, but I am not satisfied with myself" (woman B).

The second category involved participants who have past experiences of having children and were in this situation before. Although this was not a new experience for them, still they are fighting to accommodate all the responsibilities. One of the participants mentioned that:

"With the fourth child, the responsibility is increased. There is no leisure time at all, no afternoon sleep, I can't go out of home, and I can't have any leisure time with friends because I don't have any one to leave my children with. I feel that my shoulders are coming down and my back is curving because of tension" (Woman K).

Therefore with all these tasks, they could not find time for themselves including weight reduction or shopping. Some participants have help from others, for example asking their mothers to do the shopping for them. As one of the participants said:

"I feel that my priority is to meet the needs of my children, my husband, and my house, then my work is the last thing. I try to think about myself, but I find that time is over and no time is left to take care of myself. I rarely find time for myself" (woman N).

Participants found it difficult to take care of their personal needs. For example, some of them buy cosmetics because they could not find time to visit the beauty centers while others felt that they could not lose the weight they gained during pregnancy because they do not have enough time to go to fitness centers.

(woman D said: "It is difficult to find enough time for my baby daughter, so how could I find for myself? The time of the day is short and I hope if there are more 3 or 4 hours just to take care of the basic needs of myself, without the luxuries like going to a beauty center or going to café with friends".

As a transition and an adjustment, most of the participants feel socially isolated because they do not have time for any other people except their family and there is no time for social relationships. One of the participants said:

"I suffer since I am socially zero and most of the social events are cancelled because of work. For me, I neglect myself too much, I do not care for myself, and I don't 
care for going out of home even for buying clothes, but just accomplishing the important things. When I have a two-day vacation, I visit my family" (woman $H$ ).

Challenges to balance between work and childcare, the need for more maternity leave: All the participants in the study assert that the days allotted for maternity leave are insufficient whether 70 days or 90-days. They stated an urgent need to expand this period because it is not enough for the mother or the baby. In addition the baby still needs breastfeeding. One of the participants said:

"It is 70 days period of time, the baby is still very small, the mother returns to work but her child needs her presence increasingly. The decision makers who specify the time of the maternal leave should consider this and increase the period or give mothers some facilities......." (woman I).

Sometimes the mother or the child were exposed to several health problems during the period of maternity leave and because of this there was an urgent need for an additional vacation; as one of the participants said:

"The maternity leave wasn't enough, I spent half of it in the hospital with my son because he had high degree of jaundice and I gave birth before my due date, so his weight was little and they put him in the incubator. Even if my son was well, the maternity leave wouldn't be enough to ensure that the baby is good and know more about what he needs...." (woman B).

The workplace circumstances may stand as another obstacle to have a long maternity leave. Participants discussed how work responsibilities take the first priority from the points of view of the administrators. In the health care sector, where work involves caring for humans, the need of a working mother is not comparable. Particularly when there is a shortage of staff, women are forced to return to work as soon as possible and this is in opposition to their responsibilities as mothers and as housewives. Some of the participants mentioned that:

"........According to the Labor Law I have three months with salary as a maternity leave and it can be extended up to one year without salary, but I couldn't extend my leave more because there is a lack of staff at my department" (woman A).

\section{Theme 2: Requirements of multi roles mother (nursing/working)}

The need for a trusted daycare: Getting back to work after maternal leave is surrounded by many challenges to the working mother. These challenges include the process of finding a suitable and trusted child care facility. The participants mentioned the difficulties they usually face in searching for a daycare that is near to home or work and which can appropriately take care of the physical and emotional needs of the baby and most importantly can be trusted as a replacement of the mother. Some of the participants mentioned that the child care facility is usually located in a place that is very far from the work. This increases transportation time after work to pick up the baby. One of the participants said:

"...Although I know that I will need a nursery because we have no one to take care of the new child... we could not find a close nursery and all of them are too far and even very expensive.. It took me half an hour to reach the nursery" (woman D).

Participants also faced a conflict in selecting the right daycare. This was related to the large number of children in the facility where one NAN is taking care of 6-7 babies at the same time. Another concern was the fear of the baby becoming ill from exposure to other children. As one of the participants said:

"...According to my work, I see many problems because of nurseries; children have diseases from each other. Also, I know my daughter that she doesn't sleep or eat easily, so I am afraid that the baby sitter may become angry at her because of her behaviors, and they may not try more than two times to feed her if she refuses food thinking that she does not want to eat, while I am trying three to ten times until she eats because I am her mom. In addition, if she takes any disease from other children, she will take an antibiotic for it and may have to enter the hospital. I do not like to suffer from these things until I have a choice to leave my daughter with mum" (woman D).

She also said "she can't stay with mum too long, but putting her in a nursery in the age of one year would be a little bit better than to be three months old so that she can express herself if she is sad or angry and she will have good immunity. So, the choice of putting my daughter in a nursery exists, but I will not use it as long as mum is accepting my daughter to stay with her" (woman D).

Most of the participants mistrusted the day care from previous negative experiences. Putting their child in a childcare center would be the last possible choice for them. They would prefer to select a babysitter or put them with one of her relatives in order to ensure that no harm might happen to her child.

"I have a background about nursery that the child does not receive full care like when I put him with one of my family members or one relative. I mean that our families will be the best choice; the child will mix with other children, so the environment cannot be suitable for a child, especially for a baby. I heard from the people and heard some stories from my friends about nurseries. So, I have a bad image of the nursery, and that is why I and my husband are against the idea of the nursery" (woman H).

Some of the participants had the opportunity to put 
or keep their children with their mothers or mothersin-law while others introduced the idea of having a servant, especially if the money is available. In addition to all the disadvantages of the nursery, it is still very costly.

"After I return to work, the servant is responsible for the baby until I return to home. At home, I sometimes do everything for her or the servant because she knows the times of changing the baby's diaper. I ask the servant to take care of the baby when I am busy teaching children" (woman S).

"I leave my child with a lady of my relatives and she lives near my home. I never think to put him in a nursery because there are many children and they become sick quickly, but this lady has one child" (woman E).

Another participant said: "I leave my children with a lady who has been working as a baby sitter inside her home for 12 years and she lives near my home. My colleague also puts her children with this lady too. I'm not thinking of finding a nursery because I feel very comfortable with her and I never think of changing the place. Moreover, I need a nursery that works 24 hours, but this is not available in Jordan" (woman C).

Most of the participants mentioned that there is a risk when dealing with the daycare. For example, the child would exposed to illnesses and poor care. Therefore, they preferred the option of remaining under the auspices of the family instead of being exposed to health risks and poor attention.

"I experienced the nursery with my daughter, she became sick many times, her immunity wasn't that good, and she was affected psychologically until she became elder. In my opinion, I think that all nurseries are bad and I do not think it is a safe choice to put my son in any nursery. Now, I leave my son with a lady at her home which is near my home. She takes money more than the nursery, but I pay more in order to offer a better place for my child to look after him during my work time" (woman A).

The intervention with work and the need for support: Direct support from family members and close friends help many participants to face the challenges after childbirth and make the transitional experience much easier. The majority of people who provide support for working women are; husbands, parents, mothers in-law, siblings and close friends.

All the participants in this study said that they received a source of help and encouragement from close family members. Most of the participants mentioned many forms of support such as helping with house cleaning and tidying, helping with childcare, providing emotional and physical help, and bearing the responsibilities of the baby sitter when the participant is at work.

The majority of the participants mentioned that their husbands are the most supportive person for them; his presence among his children is one of the most important reasons for support to working women. One of the participants said:

"My husband supports me a lot in taking care of children and home works; he helps me if I want to bathe them, he changes their diapers without asking him to do that, washes the dishes when we finish eating while I breast-feed the children. He helps me and complete cooking if the children need me as well as folds and tidies the clothes after washing them. He encourages me to breast-feed our child...." (Woman C).

Most of participants pointed out the importance of the presence of the supportive mother (the grandma of the child). The presence of the grandma makes the participants feel more comfortable and adds to the feeling of security when she is at work. In addition to getting the assistance regarding the care of children and fulfilling several household duties, the participants receive a psychosocial support from a well-experienced mother such as the grandma, and this helps the working mother feel that this is the most important form of support. One of the participants said:

"Mum is the first supporter for me, she helps me in cooking and my mother in law sometimes also helps me in cooking because she lives near my home. My husband supports me especially in fulfilling home duties; he washes the dishes if my daughter cries so as I can look after her and usually irons his clothes" (woman D).

Other participants mentioned that the emotional support they get from their mothers or mothers in-law helped them to cope with their life and accept the fact of leaving the child at home and going to work.

"... I was worried if I could leave my son, my mum told me that she would try to take him and she accepted because my child is calm. My husband also supports me, he is a new retired, so he sends our children to school and prepares them, then he usually does the household chores" (woman J).

Other support comes from close family members as a working woman's sister usually offers help and provides childcare for the children. One participant mentioned;

"I carried him all the time when he cried. But, mum and my sister supported me too much even after returning to work. They do now everything for him before I arrive from work like bathing, feeding and changing clothes...." (woman B).

"The most supporter is my family, especially mum, my sisters, and my husband. He wakes up before me in the morning, prepares himself, brings me to work, takes me from work, helps me in home works as well as in looking after our son, Mum supports me too much; she takes care of my son, he stays for a long time with her and I leave him with her if I want go out during the weekends, too". (woman I). 
Taking care of the child by the family of her husband especially (mother in law) would make the transition to work much easier and facilitate the process of leaving her baby. One of the participants said:

"....... The biggest support is from my husband's family because they have my child, take care of him, and do everything. we usually eat at my husband's family home and do not enter my home too much, so it stays clean. My family supports me psychologically because they live far away from my work" (woman $G$ ).

Some of the participants said that they get some kind of help from their colleagues such as: Reducing their workload and getting support so as she can continue her vacation.

"I thought of taking additional two months vacation, but my colleagues collaborated with me. They did not make me take this vacation; so I went to the clinic on my day and go back home for the rest of the days (it was like a vacation without salary), so I just work on my clinic's days" (woman M).

\section{Other participants said:}

"Because 70 days were not enough, and I would take more days if I had the chance. However, the priority is for the department, the supervisor agreed because there was another nurse who covered my place" (woman C).

Few of the participants have some reservations about the support they get from their workplace (colleagues and the supervisor) especially with regards to work requirements.

"There is no support from colleagues or from the department. My shifts are not consistent with my husband's shifts, so no one can cover my work if I need a holiday or if I have to leave work early in order to see my son", (woman G).

Moreover, some women have some source of support, such as using domestic help from cleaners and maids that reduced the time they usually spend on household tasks. One of the participants said:

"I had a servant during the maternity leave, but I did not make her touch my baby because my daughter was newly-born and still very small. So, I did everything for my daughter; changing clothes, feeding, sleeping, and everything for her. After returning to work, the servant is responsible for the baby until I return to home from work. At home, I sometimes do everything for my child or the servant because she knows the times of changing the baby's diaper. I also ask the servant to take care of the baby when I am busy teaching the children. When I had a short visit out of home, I usually tell the servant not to feed the baby, but if I know that I am going to be late, I ask her to give the baby milk" (woman S).

\section{Discussion}

Two themes were identified by the women that participated in the study. These themes are: A new life with burdens, errands and tasks, Requirements of multi roles mother.

The aim of this research was to explore the experience of the Jordanian women working in Healthcare three months after returning to work from maternity leave. The focus of the research was centered on motherhood life, family and work relationships as well as her role after returning to workplace.

In order to achieve the aim of this study, the researcher formulated three objectives of this study, discussed the findings according to these objectives. This chapter provides a contextual meaning of the findings within the wider literature. The period after the return from maternal leave makes the working mother face multiple challenges as a result of these transitions, the women try to fulfill their responsibilities but frequently question their capabilities as good mothers.

1. The women's experience of role alteration after returning to work from maternal leave: (A new life with burdens, errands and tasks);

2. Struggling between being working women and being a mother.

Many Jordanian working women scrape through life while being overwhelmed by responsibilities and duties. All of these responsibilities form a burden on the working women who are trying to fulfill their roles. They tend to feel disorganized, less focused, lost, and out of control while sustaining physical and psychological stress. Because the new role of being a working mother is added to them on top of their previous jobs of wife and homemaker.

In Jordan, the presence of some traditional social standards distribute the duties traditionally between men and women unjustly. Women bear alone the full burden of childcare and household work (Department of statistics \& The Jordanian National Commission For women, 2008) [11]. As a result, working women feel exhausted and stressed as they work to achieve a balance between home and work responsibilities. When working women have children, their priorities change which may lead to a decreased commitment to their career. Moreover, some mothers altered their own way of life in order to match the baby's rhythm resulting in changes in their relationships with their spouse and extended family.

Because of the multiple roles and responsibilities, Jordanian working women are socially isolated and have no time to start new relationships or social activities. These findings are consistent with Spiteri and Xuereb [10] who was conducted research in 2012 with 10 Maltese women.

Spiteri and Xuereb [10] found that going back to work had a obligatory adjustment period and the return 
to work disrupted their life. Moreover, women felt a sort of losing control over decision-making and over the process of rearing the child. Also, they were faced with a role overload and struggled with time management. They changed their relationships with their spouses, infants and with themselves because of their changing priorities. Moreover, this expands a UK study which was conducted by Choi, et al. [12], which reported that the participants' felt overwhelmed and unable to meet the demands placed upon them by others.

Consequently, the influence of having multiple roles for Jordanian working mothers has significantly removed women from the workplace. Currently only $13 \%$ of the Jordanian workforce is made up of women Department of Statistics (2015).

In addition, the analysis of data from the pension scheme of the Social Security Corporation (SSC) of Jordan during 2008-2013, indicates that $78 \%$ of married working women pull out of work for various reasons. In general, these reasons were related to the increase of the domestic burden due to children and the scarcity of reliable safe childcare.

\section{Requirements of multiple roles mother (Mother- ing/Working): A trusted day care}

Returning to work is a complex process; especially if working women did not find an appropriate person or location for childcare.

The women in this study have also identified the role of day care centers as a key player of adapting to the transitional life after going back to work. They claimed that the majority of day care centers were not safe or appropriately staffed to meet the needs of children, especially infants. Most women spoke about the lack of cleanness and high cost in the centers. Liu, et al. [8] found that mothers who changed their child care arrangements, between child care centers, relatives and neighborhood centers, since their child's first birthday were more likely to quit their job because of problems arranging or keeping at child care arrangement. Moreover, mothers using multiple child care providers are more likely to lose their jobs due to child care disruptions.

The study findings suggested that working women was closely dependent on their relatives and close family members to care for their newborn baby. These women felt grateful to have family members (mother, mother in law, relatives) who are available to care for their child. This facilitated a smooth transition back to work for these women. Unfortunately family is not always an option. Finding a safe, affordable day care center that is close to work or home can be an overwhelming challenge. Additionally women that work in healthcare may need childcare during unconventional hours. For example childcare may be required overnight. Appropriate childcare may encourage mothers to easily return to work after maternal leave.

These findings were supported by Spiteri and Xuereb [10] who demonstrated that Maltese mothers are much more comfortable with family taking care of the child than utilizing institutional daycare centers. It is apparent that working mothers struggle with trust issues.

\section{Limitation of the Study}

There were some limitations of this study; the researcher interviewed the women only one time after maternal leave, it might be that a longitudinal study can provide more in-depth information about the change of the women's experiences over time. There was differences in the time of conducting the interviews. Some women interviewed after three months while other women interviewed after six months or later. This might have had an impact on the women's experiences. The women included in this study where all recruited from governmental sectors. The working women in private sectors may have different experiences.

\section{Recommendations and Implications}

Based on the findings and the conclusion of this study, the following recommendations are suggested in the areas of education, practice, and research.

The transition to workplace after maternity leave needs some planning, support and collaboration from the family and the workplace.

Jordanian working women require health education, and promotion programs about the importance of time management.

The findings of this study suggested a call for policymakers to reconsider the period after child birth and maternity leave for Jordanian working mothers. Extension of maternity leave to 5-6 month would positively affect the women's productivity at work and create new ways to achieving a breast feeding continuity and strengthening the mother's and children's health as well as the bond between them. In addition, policy makers should create strict laws that govern childcare centers. Centers that care for children must be safe, well-staffed and clean to adequately care for Jordan's most fragile citizens.

This study has found several inappropriate child care arrangements (mistrust of the day care) which is associated with working mothers leaving employment. Special efforts are needed to promote access to $s$ qualified, convenient and affordable child care arrangements.

The findings of this study may be transferred to many working women in healthcare including physicians, dentists and nurses. The managers and education center in the hospital can utilize the findings of 
this study in their work environment when they plan to develop their strategic planning and initiatives for staff improvement and empowerment.

\section{Conclusion}

The experiences of working Jordanian women returning to work after maternity leave is challenging, complex and unpleasant. They struggle to meet the emotional, social and physical needs of a nursing mother and that of an employee. Jordanian women in this study felt passionate about the need for extended maternal leave in order to cope with multiple roles and responsibilities, Social support from close family members' such as husband, mother, mother-in-law, helped to facilitate the transitional experiences when the women returned back to work after maternity leave. In contrast, women found minimal support from the workplace system, especially in relation to their breast feeding hours and baby care needs. These difficulties frequently led to a decision to leave work in order to care for the new child.

Jordanian working women are an integral and valuable part of the workforce. Childbirth is an expected event that is part of the social fabric in Jordan. Subsequently policies need to be created that support and protect working women and their young children. After all, without healthy women and children Jordan has no future [13-54].

\section{References}

1. Pixey JE (2008) Life course patterns of career- prioritizing decisions and occupational attainment in dual- earner couples. Work and Occupations 35: 127-163.

2. Deniz N, Deniz S, Ertosun ÖG (2012) The Woman-friendly organization-effects of demographic variables on women employees' perception about their companies on work and family-oriented woman-friendly HRM: A study in banking industry in turkey. Procedia-Social and Behavioral Sciences 41: 477-484.

3. Coulson M, Skouteris H, Dissanayake C (2012) The role of planning, support, and maternal and infant factors in women's return to work after maternity leave. Family Matters 90 .

4. Khalil M (2009) Jordanian National Commission for Women, The national Report for the Hashemite Kingdom of Jordan.

5. Aguirre D, Hoteit L, Rupp C, Sabbagh K (2012) Empowering the third billion: Women and the world of work in 2012. Booz and Company.

6. Alstveit M, Severinsson E, Karlsen B (2011) Readjusting one's life in the tension inherent in work and motherhood. $J$ Adv Nurs 67: 2151-2160.

7. Fursman L (2002) Ideologies of motherhood and experiences of work: Pregnant women in management and professional careers. Working Paper 34: 1-10.

8. Liu M, Chen M, Anderson SG (2014) Factors influencing child care-related maternal work exits. Children and Youth Services Review 46: 168-176.

9. Clark AM (2012) A phenomenology of the meaning of motherhood for african american and hispanic women who do not have children in the United States. Digital Commons,
University of Nebraska - Lincoln Sociology Theses, Dissertations, \& Student.

10. Spiteri G, Xuereb RB (2012) Going back to work after childbirth: Women's lived experiences. Journal of Reproductive and Infant Psychology 30: 201-216.

11. The general statistics department \& The Jordanian National Commission For women (2008) The participation of women in the labor sector unregulated. National survey.

12. Choi P, Henshaw C, Baker S, Tree J (2005) Supermum, superwife, supereverything: Performing femininity in the transition to motherhood. Journal of Reproductive and Infant Psychology 23: 167-180.

13. Abdalrahim MS, Zeilani R (2014) Jordanian survivors' experiences of recovery from critical illness: A qualitative study. Int Nurs Rev 61: 570-577.

14. Amir LH, Donath SM (2008) Socioeconomic status and rates of breastfeeding in Australia: evidence from three recent national health surveys. Med J Aust 189: 254-256.

15. Baker M, Milligan K (2008) Maternal employment, breastfeeding, and health: Evidence from maternity leave mandates. Journal of Health Economics 27: 871-887.

16. Baxter $\mathrm{J}(2008)$ Is money the main reason mothers return to work after childbearing? Journal of Population Research 25: $141-160$.

17. Booz, Company Alfalah R (2001) The impact of maternity leave on the reproductive behavior for the teachers in the public sector - a case study - The first Breeding Amman Directorate. Jordan University.

18. Beauregard TA, Henry LC (2009) Making the link between work-life balance practices and organizational performance. Human Resource Management Review 19: 9-22.

19. Blumberg RL (1991) Gender, family, and Economy The Triple overlap. A Sage Focus Edition International Educational and Professional Publisher Newbury park, London, New Delhi.

20. Broussard $L$ (2006) Understanding qualitative research: $A$ school nurse perspective. J Sch Nurs 22: 212-218.

21. Brown GW, Andrews B, Harris T, Adler Z, Bridge L (1986) Social support, self-esteem and depression. Psychol Med 16: 813-831.

22. Chuang $\mathrm{CH}$, Chang PJ, Chen YC, Hsieh WS, Hurng BS, et al. (2010) Maternal return to work and breastfeeding: A population-based cohort study. Int J Nurs Stud 47: 461-474.

23. Collins PH (1991) Black feminist thought: Knowledge, consciousness and empowerment. Boston, MA: Unwin Hyman.

24. Conti M, Sette E (2013) Type of employer and fertility of working women: Does working in the public sector or in a large private firm matter? Cambridge Journal of Economics 37: 1303-1333.

25. Crompton R Lewis S, Lyonette C (2007) Women, men, work and family in Europe, Palgrave Macmillan.

26. Crookes PA, Davies S (2004) Research into practice: Essential skills for interpreting and applying research in nursing and health care.

27. Dagher RK, Hofferth SL, Lee Y (2014) Maternal depression, pregnancy intention, and return to paid work after childbirth. Women's Health Issues 24: 297-303.

28. Deleon CW (2012) A pilot study on perceptions of sleep deprivation and mother-infant interaction. Journal of the Indiana Academy of the Social Sciences 15. 
29. Elborgh-Woytek MK, Newiak MM, Kochhar MK, Fabrizio MS, Kpodar K, et al. (2013) Women, work, and the economy: Macroeconomic gains from gender equity: International Monetary Fund.

30. Giallo R, Cooklin A, Dunning M, Seymour M (2014) The efficacy of an intervention for the management of postpartum fatigue. J Obstet Gynecol Neonatal Nurs 43: 598-613.

31. Graneheim UH, Lundman B (2004) Qualitative content analysis in nursing research: Concepts, procedures and measures to achieve trustworthiness. Nurse Educ Today 24: 105-112.

32. Grady G, Mc Carthy AM (2008) Work-life integration: Experiences of mid-career professional working mothers. Journal of Managerial Psychology 23: 599-622.

33. Horne J, Corr S, Earle S (2005) Becoming a mother: A study exploring occupational change in first-time motherhood. Journal on Occupation Science 12: 176-183.

34. Houston DM, Marks G (2003) The role of planning and workplace support in returning to work after maternity leave. British Journal of Industrial Relations 41: 197-214.

35. Johnston ML, Esposito N (2007) Barriers and facilitators for breastfeeding among working women in the United States. J Obstet Gynecol Neonatal Nurs 36: 9-20.

36. Killien MG (2005) The role of social support in facilitating postpartum women's return to employment. J Obstet Gynecol Neonatal Nurs 34: 639-646.

37. Lucas-Thompson RG (2012) Associations of marital conflict with emotional and physiological stress: Evidence for different patterns of dysregulation. Journal of Research on Adolescence 22: 704-721.

38. Maheshwari M (2014) Dynamics of Being a 'Good Employee' and a 'Good Mother': Dilemmas of Professional Indian Working Women. Indian Institute of Management Udaipur Research Paper Series.

39. Marks G, Houston DM (2002) Attitudes towards work and motherhood held by working and non working mothers. Work, Employment and Society 16: 436-523.

40. Morris L (2008) The experiences of women returning to work after maternity leave in the UK. Summary of survey results.

41. Parcsi L, Curtin M (2013) Experiences of occupational therapists returning to work after maternity leave. Aust Occup Ther J 60: 252-259.
42. Patton MQ (2002) Qualitative interviewing. Qualitative research and evaluation methods 3: 344-347.

43. Pearson QM (2008) Role overloaded, job satisfaction, leisure satisfaction and psychological health among employed women. Journal of Counseling and Development 86: 57-63.

44. Peebles D, Darwazeh N, Ghosheh H, Sabbagh A (2007) Factors affecting women's participation in the private sector in Jordan. National Center for Human Resources Development, Canadian International Development Agency, Canada.

45. Polit DF, Beck CT (2013) Essentials of nursing research: Appraising evidence for nursing practice. Lippincott Williams \& Wilkins.

46. Russell H, Banks J (2011) Pregnancy and employment: A literature review.

47. Marie-Josèphe Saurel-Cubizolles, Patrizia Romito, Vicenta Escribà-Aguir, Nathalie Lelong, Rosa Mas Pons, et al. (1999) Returning to work after childbirth in France, Italy, and Spain. European Sociological Review 15: 179-194.

48. Schott W (2012) Going back part-time: Family leave legislation and women's return to work. Popul Res Policy Rev 31: $1-30$

49. Sharkey KM, Iko IN, Machan JT, Thompson-Westra J, Pearlstein TB (2016) Infant sleep and feeding patterns are associated with maternal sleep, stress, and depressed mood in women with a history of major depressive disorder (MDD). Arch Womens Ment Health 19: 209-218.

50. Speziale HS, Streubert HJ, Carpenter DR (2011) Qualitative research in nursing: Advancing the humanistic imperative. Lippincott Williams \& Wilkins.

51. Stockard J, Lehman MB (2004) Influences on the satisfaction and retention of 1 st-year teachers: The importance of effective school management. Educational Administration Quarterly 40: 742-771.

52. Tomlinson J, Olsen W, Purdam K (2009) Women returners and potential returners: employment profiles and labour market opportunities-a case study of the United Kingdom. European Sociological Review 25: 349-363.

53. Valk R, Srinivasan V (2011) Work-family balance of Indian women software professionals: A qualitative study. IIMB Management Review 23: 39-50.

54. Van Gennep A (1960) The rites of passage (MB Vizedom, GL Caffee Trans). London: Routledge. 